\title{
Posture and gastro-oesophageal reflux: a case for left lateral positioning
}

\author{
Jacinta M Tobin, Phillip McCloud, Donald J S Cameron
}

\begin{abstract}
Aim-Prone posture is often recommended for symptomatic gastrooesophageal reflux in young infants, but prone positioning has been associated with sudden infant death. The aim of this study was thus to establish the optimal alternative posture for reducing reflux. Methods-24 infants ( $<5$ months) with symptomatic gastro-oesophageal reflux were studied prospectively with $48 \mathrm{~h} \mathrm{pH}$ monitoring. They were randomly assigned to one of the 24 permutations of the four positions (supine, prone, right, left). During the first 24 hours the infant was held horizontally, and then the permutation was repeated at 30 degrees head elevation, giving a total of eight study segments for each infant. Data were edited to remove all time when the infants were not in the prescribed positions. Results were evaluated using analysis of covariance.

Results-Gastro-oesophageal reflux expressed as reflux index (mean \% (SEM)) was significantly less in the prone and left lateral positions (6.72 (1.06) and 7.69 (1.03) respectively) than in the supine and right lateral positions (15.33 (2.33) and 12.02 (1.38); $p<0.001)$. Head elevation did not affect any variables significantly. Conclusions-Head elevation may not always be of clinical value. The left lateral position is a suitable alternative to prone for the postural management of infants with symptomatic gastro-oesophageal reflux.

(Arch Dis Child 1997;76:254-258)
\end{abstract}

Keywords: gastro-oesophageal reflux; positioning; sudden infant death.

Monash Medical Centre, Clayton, Victoria, Australia: Monash University Department of Paediatrics J M Tobin

Monash University Department of Mathematics

P McCloud

Paediatric Gastroenterology Unit D J S Cameron

Correspondence to: Dr Jacinta Tobin, Institute of Child Health, Francis Road, Birmingham B16 8ET.

Accepted 4 November 1996

Postural treatment has been a traditional part of the management of symptomatic gastrooesophageal reflux in infancy. A variety of measures has been tried, including infant seats and elevation of the head of the cot. ${ }^{12}$ However, in small infants with poorly developed truncal control, sitting upright can lead to slumping, which in turn may increase intraabdominal pressure and reflux..$^{3-5}$ Prolonged oesophageal $\mathrm{pH}$ monitoring has allowed evaluation of gastro-oesophageal reflux under various conditions, and previous studies have shown an advantage for prone position compared with supine ${ }^{6}$ or the infant seat, ${ }^{7}$ although the effect of elevation remains debatable. ${ }^{8}$ The association between the prone sleeping position and sudden infant death has led to concerns about recommending this position. ${ }^{9-11}$ Some have continued to advocate the prone position for infants with gastrooesophageal reflux, ${ }^{12}$ but this would be unnecessary if a comparable alternative could be found.

There are no published studies which adequately explore lateral positioning in infants with symptomatic gastro-oesophageal reflux, and particularly the next best position to prone. ${ }^{13-15}$ The right lateral position, with head elevation, is often recommended on the grounds that the pylorus is on the lower side and that gravity assists gastric emptying, resulting in less reflux. However, this is an instinctive view, which requires further evaluation.

The aims of this study were to evaluate prospectively the effects of position and elevation in young infants with symptomatic gastrooesophageal reflux and a reflux index of greater than 5\%. Prolonged oesophageal pH monitoring would be used to assess the relative amount of reflux in each of four positions (supine, prone, left, and right), both horizontally and with head elevation. The study was designed to allow for the effects of circadian rhythm, ${ }^{16} 17$ and for time out of position, with each infant as their own control.

\section{Methods}

SAMPLE

The power calculations before the study showed that with $\alpha=0.05$, power $=0.8$, and 'within infant' deviation of 7.5, a sample size of 16 was required to detect an absolute difference of $5 \%$ (reflux index) between two positions. Four different positions provide 24 possible permutations, so in order to use the full set, the sample size was increased to 24 .
SELECTION

Infants were referred to the Monash Paediatric Gastroenterology Unit by paediatricians for evaluation of possible gastro-oesophageal reflux. Between May 1992 and May 1994, 60 consecutive infants were referred who fulfilled our eligibility criteria. These were prospectively enrolled for 48 hour $\mathrm{pH}$ monitoring.

Infants more than four days post-delivery and less than 5 months of age, with no previous gastrointestinal surgery, were eligible. The upper age limit was chosen because of the difficulty in maintaining a mobile infant in position. Nursing in an open cot and at $30^{\circ}$ elevation had to be possible. Prokinetics and histamine-2 receptor antagonists were ceased at least 48 hours earlier, with antacids and 
Table 1 Time periods and reflux indices for eight positions. Duration of $p H$ monitoring in each position: unedited periods: then edited periods. Reflux indices for each of the eight positions for edited periods

\begin{tabular}{|c|c|c|c|c|c|c|c|c|}
\hline Variable & Supine & $\begin{array}{l}\text { Supine } \\
30^{\circ}\end{array}$ & Prone & $\begin{array}{l}\text { Prone } \\
30^{\circ}\end{array}$ & Left & $\begin{array}{l}\text { Left } \\
30^{\circ}\end{array}$ & Right & $\begin{array}{l}\text { Right } \\
30^{\circ}\end{array}$ \\
\hline \multicolumn{9}{|l|}{ Unedited time } \\
\hline SEM & 7.4 & 5.8 & 5.3 & 5.6 & 7.8 & 5.8 & 6.4 & 6.1 \\
\hline Edited time (min) & 267.4 & 278.1 & 279.3 & 285.7 & 275.5 & 277.0 & 276.5 & 286.1 \\
\hline SEM & 11.2 & 11.2 & 9.2 & 10.2 & 12.2 & 13.1 & 12.9 & 9.9 \\
\hline Reflux index (\%) & 14.5 & 16.2 & 8.2 & 5.2 & 8.4 & 7.0 & 11.9 & 12.1 \\
\hline SEM & 2.6 & 3.9 & 1.7 & 1.2 & 1.4 & 1.6 & 1.8 & 2.1 \\
\hline \multicolumn{9}{|l|}{$\begin{array}{l}\text { No of } \\
\text { episodes/edited }\end{array}$} \\
\hline $\begin{array}{l}\text { time } \\
\text { SEM }\end{array}$ & $\begin{array}{l}8.2 \\
1.2\end{array}$ & $\begin{array}{l}6.0 \\
0.9\end{array}$ & $\begin{array}{l}4.4 \\
0.8\end{array}$ & $\begin{array}{l}4.1 \\
0.7\end{array}$ & $\begin{array}{l}6.3 \\
1.0\end{array}$ & $\begin{array}{l}5.4 \\
1.3\end{array}$ & $\begin{array}{l}6.3 \\
0.9\end{array}$ & $\begin{array}{l}4.8 \\
0.7\end{array}$ \\
\hline \multicolumn{9}{|l|}{ No of episodes $>5$} \\
\hline SEM & 0.3 & 0.4 & 0.3 & 0.2 & 0.6 & 0.2 & 1.2 & 0.2 \\
\hline \multicolumn{9}{|l|}{ Longest episode } \\
\hline$(\min )$ & 21.5 & 24.3 & 12.7 & 8.4 & 12.3 & 12.7 & 19.6 & 23.2 \\
\hline SEM & 4.6 & 7.1 & 2.8 & 2.7 & 2.8 & 4.1 & 4.5 & 5.5 \\
\hline
\end{tabular}

Values have been rounded to a single decimal place.

thickening agents the day before. Informed consent was obtained from all parents in accordance with the guidelines of the ethics committee of the Monash Medical Centre, which had approved the study.

Each infant was assigned a set of positions (for example: prone, supine, right lateral, left lateral, held horizontally during the first 24 hours, then elevated), randomly drawn from the 24 envelope set of all possible permutations, before $\mathrm{pH}$ monitoring. This gave each infant a block of eight segments of six hours.

For an infant to remain in the study required a reflux index of greater than $5 \%$ during the first 24 hours of horizontal monitoring, a technically satisfactory study, and all time accounted for with a completed diary of observations performed with the baby rotating through the correct position permutation. Twenty seven were excluded because of a reflux index of less than $5 \%$, six for technical reasons, and three because of inadequate diary completion. For each infant disqualified, that set of positions went back into the envelope set until all 24 sets were taken up by qualified study subjects.

Of the 24 included, 15 had reflux indices between $5.2 \%$ and $10 \%$, and nine were greater than $10 \%$. The mean age was 2 months, and there were 13 females and 11 males. Only one third of the infants were exclusively breast fed. The predominant symptoms experienced were vomiting (20) or poor feeding (4), with irritability (11), choking/apnoeic spells (10), or weight concerns (3).

\section{MEASURES}

Each infant was assigned a set of positions according to the study design. Monitoring was begun as close to 1300 hours as possible. Synectics $\mathrm{pH}$ monitoring equipment (Synectics Medical, Sweden) was used. The monocrystalline antimony $\mathrm{pH}$ electrode was calibrated using the Synectics pH 1.07 and 7.01 buffer solutions, respectively. The $\mathrm{pH}$ probe was placed in the lower oesophagus by one of the two investigators using Strobel's ${ }^{18}$ formula to calculate naso-oesophageal distance. In all cases this was confirmed by an abrupt fall in $\mathrm{pH}$ at this distance to below $\mathrm{pH} 4$, often accompanied by a palpable sensation of lessening resistance as the stomach was entered. The probe was then withdrawn to seven eighths of the calculated naso-oesophageal distance and left there for 48 hours. Data were stored in the Mark III Digitrapper. After a period of tube adaptation, recording was started from the time the infant was put in the first assigned position. A detailed handwritten diary was kept by the nurse-parent team, with optional confirmatory input using the electronic event markers. Particular note was taken of actual position times, with all reasons for time out of position recorded, as well as infant behaviour. The infants were fed breast milk or formula according to their normal feeding schedule. Parents were encouraged to leave their infants in position as much as possible, to feed only at their scheduled times and to put them back down promptly. The infant was maintained in each position by placing the lower shoulder forward to stabilise the side lying position, careful swaddling, towelled bolsters on either side, and cloth support in the elevated position. A cardiorespiratory monitor was attached if there was concern about the inclusion of the prone position.

The data were first analysed using the EsopHogram software program (Gastrosoft Inc, Synectics Medical, Sweden) with an episode of acid reflux defined as an abrupt fall in intraoesophageal $\mathrm{pH}$ to less than 4 for at least 15 seconds. The standard variables were used including the reflux index (percentage time $\mathrm{pH}$ was less than 4), number of episodes, number greater than five minutes, and longest episode.

For each of the eight positions in each infant (four horizontal and four elevated), nearly six hours of data were obtained. However, it was recognised that infants would not necessarily be in the designated position for the whole six hours because of feeds or other activities. Therefore each six hour period was also edited to remove those periods of time (and corresponding $\mathrm{pH}$ data) when the infant was out of position ('edited' results). The edited time periods were reduced-but to a mean of more than four hours per position (table 1) - for each of the eight segments (range 137 to 380 minutes). Data were adjusted statistically for these varying periods as an integral part of the analysis.

\section{STATISTICAL METHODS}

The study contained two treatment factors: first the position of the infant (right, left, prone, and supine); and second the elevation of the infant $\left(0^{\circ}\right.$ and $\left.30^{\circ}\right)$. The levels of the two treatment factors were combined into a $4 \times 2$ factorial and each infant received all eight combinations of position and elevation. For practical reasons the elevation was not randomised, with infants receiving their first four positions in the horizontal position (day 1), and their last four in the elevated position (day 2), which is a 'split plot' design. The reflux activity data were analysed by analysis of covariance (ANCOVA). The treatment factors included in the analysis as main effects were 
Table 2 Results by position

\begin{tabular}{|c|c|c|c|c|c|c|c|}
\hline Variable & Supine mean & Prone mean & Left side mean & Right side mean & SEM & $p$ & $L S D$ \\
\hline Mean time (min) & 272.8 & 282.5 & 276.5 & 281.3 & - & - & - \\
\hline Reflux index (\%) & 15.3 & 6.7 & 7.7 & 12.0 & 1.22 & $<.001$ & 3.4 prone, left < right, supine \\
\hline No of episodes/mean time & 7.1 & 4.3 & 5.8 & 5.5 & 0.57 & 0.007 & 1.6 prone $<$ supine \\
\hline No of episodes $>5$ & & & & & & & \\
\hline $\mathrm{min} /$ mean time & 1.6 & 0.9 & 0.8 & 1.3 & 0.17 & 0.003 & 0.5 prone, left < right, supine \\
\hline Longest episode (min) & 22.8 & 10.6 & 12.5 & 21.4 & 2.41 & $<.001$ & 6.7 prone, left < right, supine \\
\hline
\end{tabular}

$\mathrm{p}$ Value from analysis of covariance $(\mathrm{df}=3,134)$.

LSD=least significant difference $(\mathrm{p}=0.05)$.

Table 3 Results by elevation

\begin{tabular}{|c|c|c|c|c|c|c|c|}
\hline \multirow[b]{2}{*}{ Variable } & \multicolumn{2}{|c|}{ Horizontal } & \multicolumn{2}{|c|}{ Elevated $30^{\circ}$} & \multirow[b]{2}{*}{ Difference (SE) } & \multirow[b]{2}{*}{$t$} & \multirow[b]{2}{*}{$p$} \\
\hline & Mean & $S E M$ & Mean & $S E M$ & & & \\
\hline Mean time (min) & 274.7 & 5.7 & 281.7 & 5.5 & & - & \\
\hline Reflux index (\%) & 10.7 & 1.0 & 10.1 & 1.3 & $0.6(1.15)$ & 0.52 & 0.61 \\
\hline $\begin{array}{l}\text { No of episodes/mean } \\
\text { time }\end{array}$ & 6.3 & 0.5 & 5.1 & 0.5 & $1.2(0.69)$ & 1.75 & 0.09 \\
\hline $\begin{array}{l}\text { No of episodes }>5 \\
\text { min/mean time } \\
\text { Longest episode }\end{array}$ & 1.3 & 0.1 & 1.0 & 0.1 & $0.3(0.14)$ & 184 & 0.08 \\
\hline$(\min )$ & 16.5 & 1.9 & 17.1 & 2.6 & $0.7(2.11)$ & -0.32 & 0.75 \\
\hline
\end{tabular}

Values other than those for $t$ test have been rounded to a single decimal place.

position, time of day, and degree of elevation, as was the interaction between position and elevation. The start of treatment for each infant varied because of the clinical needs of the ward. It was impossible to get exactly six hour periods and thus the length of time each infant spent in each segment was the covariate in the ANCOVA. The ANCOVA contained three error terms: (1) between infant; (2) between day, within infant; and (3) between six hour time period within day, within infant. The split plot design required the effect of elevation to be tested against the 'between day, within infant' error term, and the effect of time of day, position, and the interaction between elevation and position to be tested against the 'between six hour time period within day, within infant' error term. Further, the effect of elevation was described as a $t$ test to aid clarity of expression.

The assumptions of the ANCOVA were assessed graphically. The residuals did not fit a normal distribution, with the error variance increasing with increasing values. Thus a square root transformation was applied to stabilise the variance, and the assumptions appeared to hold. However, the inferences of the analysis did not change after transformation, so the untransformed results are therefore legitimately reported. The treatment means have been adjusted for the covariate (the actual time period in each position). Pairwise comparisons of means were done with the least significant difference (LSD) at the 0.05 level to evaluate the differences between positions, elevation, and time of day. Both edited and unedited data were analysed.

\section{Results}

The edited results for position and elevation are reported (tables 2 and 3). The same significant relations held for unedited data, with only two minor additions, so the edited results are presented as the more conservative data (see Discussion).

\section{POSITION}

Because of the possibility that there could be an anatomical or physiological reason why elevation could affect one position differently from another, it was necessary to examine the data to see if there was evidence for such interactions. Statistically no interactions were evident on any of the reflux indices between position and elevation. Therefore, for each baby, position horizontal can be combined with position elevated (for example prone with prone elevated; table 2).

The analysis of covariance showed that the effect of position on reflux index was highly significant $(\mathrm{F}=11.27, \mathrm{df}=3,134, \mathrm{p}<0.001)$. Reflux indices in the prone and left positions were equivalent, and both less than in the right and supine positions, after applying the least significant difference $(\mathrm{p}<0.05)$.

The effect of position on frequency of episodes longer than five minutes was highly significant $(F=4.94, d f=3,134, p=0.003)$. In the prone and left positions, the number of episodes longer than five minutes was less than in right and supine positions (LSD; $\mathrm{p}<0.05$ ). Position had a significant effect on the longest episode $(\mathrm{F}=6.93, \mathrm{df}=3,134, \mathrm{p}<0.001)$. The LSD $(p<0.05)$ showed the longest episode to be less in the prone and left positions than in the right and supine positions.

The effect of position on frequency of episodes was significant $(\mathrm{F}=4.18, \mathrm{df}=3,134$, $\mathrm{p}=0.007)$. However, after applying the LSD $(p<0.05)$, only in prone were episodes of reflux clearly less frequent than in supine, with the lateral positions intermediately placed between these two.

\section{ELEVATION}

The analysis of covariance showed that the effect of elevation did not affect the reflux indices significantly. A $t$ test was also performed, which again showed the effect of elevation was not significant (table 3 ).

\section{TIME OF DAY}

To examine the effect of time of day on reflux, unedited data were used (table 4). We considered that diurnal segments were likely to be more heavily edited than nocturnal in some infants, which could produce unnecessary distortion of this effect. Time of day had a significant influence on reflux index $(\mathrm{F}=3.83$, $\mathrm{df}=3,134, \mathrm{p}=0.011)$. Further analysis (LSD: $\mathrm{p}<0.05$ ) showed that during 0100-0700 hours there was considerably less reflux than at other times. The effect of time of day on frequency of episodes was highly significant $(\mathrm{F}=20.91, \mathrm{df}=$ $3,134, \mathrm{p}<0.001)$. However, time of day was 
Table 4 Time of day; unedited data

\begin{tabular}{|c|c|c|c|c|c|c|c|c|c|c|}
\hline \multirow[b]{2}{*}{ Variable } & \multicolumn{2}{|c|}{$\begin{array}{l}\text { Afternoon } \\
1300-1900 \mathrm{~h}\end{array}$} & \multicolumn{2}{|c|}{ Evening 1900-0100 h } & \multicolumn{2}{|c|}{ Night 0100-0700 h } & \multicolumn{2}{|c|}{$\begin{array}{l}\text { Morning 0700-1300 } \\
h\end{array}$} & \multirow{2}{*}{$\begin{array}{l}\text { Analysis of } \\
\text { covariance }\end{array}$} & \multirow{2}{*}{$\begin{array}{l}\text { Significance LSD } \\
(p<0.05)\end{array}$} \\
\hline & Mean & SEM & Mean & SEM & Mean & SEM & Mean & SEM & & \\
\hline Mean time & 245.5 & 8.4 & 284.9 & 8.1 & 318.1 & 5.0 & 261.3 & 6.0 & - & - \\
\hline Reflux index (\%) & 10.2 & 1.0 & 12.2 & 1.8 & 7.4 & 1.1 & 10.9 & 2.0 & $\begin{array}{l}F=3.83 \\
d f=3,134 \\
p=0.011\end{array}$ & 3.0 Night < other times \\
\hline $\begin{array}{l}\text { No of episodes/mean } \\
\text { time }\end{array}$ & 12.0 & 1.2 & 7.5 & 1.0 & 4.2 & 0.5 & 9.8 & 0.9 & $\begin{array}{l}\mathrm{F}=20.91 \\
\mathrm{df}=3,134 \\
\mathrm{p}=0.001\end{array}$ & 2.1 Night <other times \\
\hline $\begin{array}{c}\text { No of episodes }>5 \\
\mathrm{~min} / \text { mean time }\end{array}$ & 1.6 & 0.2 & 1.6 & 0.2 & 1.1 & 0.2 & 1.4 & 0.2 & $\begin{array}{l}\text { NS } F=1.94 \\
d f=3,134 \\
p=0.13\end{array}$ & - \\
\hline Longest episode (min) & 14.6 & 2.5 & 23.4 & 3.9 & 15.8 & 2.8 & 18.3 & 3.7 & $\begin{array}{l}F=2.79 \\
d f=3,134 \\
p=0.042\end{array}$ & 6.8 Evening >other times \\
\hline
\end{tabular}

Values other than analysis of variance have been rounded to a single decimal place.

Because of the varied starting times for each segment, each segment was grouped for analysis. At least $3 \frac{1 / 4}{4}$ hours had to fall into the time periods of afternoon (13001900 hours), evening (1900-0100 hours), night (0100-0700 hours), or morning (0700-1300 hours), for each period to be analysed for the time of day factor.

not significant for number of episodes longer than five minutes, even though it was just significant for longest episode.

\section{Discussion}

This study of 24 infants with symptomatic gastro-oesophageal reflux shows that most acid reflux occurs in the supine position, with both increased frequency and increased duration of reflux episodes. The least amount of reflux was recorded in the prone position, but the reflux index and measures of duration of reflux in the left lateral position were indistinguishable from prone.

The findings relating to prone position accord with other studies. ${ }^{13-15}$ In addition, our study has shown that left lateral positioning is comparable to prone in reducing reflux index and the duration of prolonged episodes.

Our study differs from others. Blumenthal and Lealman ${ }^{13}$ used a technique of measuring the height of the column of reflux by dye staining of a cotton string in the oesophagus. They showed an advantage for prone over supine but not for either left or right lateral positions. However, their study was limited to low birthweight babies, did not assess elevation, and could only measure the worst episode during the study period. No data could be obtained in their study about the frequency or duration of individual episodes.

While Vandenplas and Sacre-Smits ${ }^{14}$ found that prone was better than supine or lateral positioning, they were not able to show a difference between supine and lateral (left or right). However, they studied only 'control' babies in the newborn period and each baby was placed in one position only for the entire study period. Their study of 'symptomatic' babies was limited to comparing prone and supine, with significant improvement only seen in those with radiologically demonstrated reflux and then only by head elevation as well as prone positioning. Frequency and duration of episodes was improved in this group. Lateral positioning was not studied in this group.

Tam and $\operatorname{Lin}^{15}$ applied similar methods to 40 asymptomatic newborns and found less reflux in the prone position than in supine or either lateral position. Again each baby was studied in only one position and the effect of head elevation was not examined.

Our data suggest that head elevation does not confer an additional benefit in reducing reflux. However, this study did not use a crossover for elevation and it is possible, although unlikely, that other factors may have been operating during the second 24 hours to obscure an elevation effect. Our study cohort was predominantly mildly affected babies, so it is still possible that those at the more severe end of the spectrum could benefit. Greater numbers might also have helped clarify this. Previously Orenstein, ${ }^{8}$ using a crossover design, found that head elevation in the prone position reduced the number of episodes but also the number of prolonged episodes postprandially.

Circadian rhythm and sleep state are important in infants over six weeks of age. ${ }^{17}{ }^{19}$ In addition Dreizzen et $a l^{16}$ have shown a definite rhythm to reflux itself, with an evening peak around 1800 hours and a nadir at 0600 hours. This was allowed for in our study by having each position represented in each time zone, to overcome the possibility that changes in reflux index were due to time of day rather than position. Our results suggested that there was a separate effect of less reflux in the overnight period (0100-0700) than at other times of the day, mainly due to reduction in the number of episodes.

Our study was designed to enable direct comparison of position and elevation, in individual symptomatic babies outside the newborn period, with reflux indices of $>5 \%$. The upper limit of normal was originally considered to be about $5 \%$ reflux index, ${ }^{20}$ but the work of Vandenplas in 1991 suggested around $10 \%$ as the 95 th centile, with $4 \%$ as the 50th centile for infants aged around 2 to 3 months. ${ }^{21}$ Personal experience suggested that if the reflux index was less than $5 \%$, then the number and distribution of episodes of reflux would be insufficient to produce meaningful results, while infants with $>5 \%$ reflux index are frequently symptomatic and could well benefit from posture.

Each position was studied for only six hours, which was reduced to a mean of more than four 
hours after editing. It is acknowledged that oesophageal $\mathrm{pH}$ monitoring should be done for a prolonged period, ideally at least 22 hours, ${ }^{22}$ and that the influence of postprandial buffering may lead to an underestimation of the overall amount of reflux (although not of acid reflux). However, we consider that this effect can be offset by the fact that each baby was their own control and that the various positions were allocated evenly throughout the day. This allowed for the possible confounding variables of diurnal variation, especially feed frequency, arousal level, and sleep. Because there was no interaction between position and elevation, the values for each position for each baby actually represent two separate four to six hour periods (one horizontal and one elevated), so that data are derived from 8-12 hours of study. Similarly, the head elevation data for each elevation are derived from four separate four to six hour periods.

Editing meant that only those times when the baby was actually in the prescribed position were used in these calculations. The time periods involving feeding, changing, and other activities out of position were noted, and the corresponding $\mathrm{pH}$ data removed before analysis. Reassuringly, the soundness of our design was supported by the analysis of the unedited data, which mirrored the edited data, with only two minor additions. In regard to position, supine now increased the number of episodes compared to all other positions, and elevation significantly shortened the longest episode. However, our 'edited data' represent the more accurate of the two versions because only time actually in position is included and this is therefore the one reported in detail.

The finding that left lateral is comparable to prone positioning in reducing reflux allows an alternative option for treatment. The left lateral position must of course be stabilised - as we have done - to prevent the infant rolling into prone, for it to be safely recommended to parents. The explanation for less reflux in the left lateral and prone positions is speculative, but there appears to be a reduction in duration rather than in frequency. While the frequency of episodes is likely to be a function of the number of times the lower oesophageal sphincter relaxes (either spontaneously or under pressure), the duration of reflux episodes will be more related to clearance by swallowed saliva or oesophageal peristalsis, and the pressure on the column of refluxate. This suggests that in the left lateral and prone positions, when the greater curvature of the stomach is able to provide an enhanced 'reservoir capacity' for gastric content in the stomach body, there will be less pressure, enabling better drainage back into the stomach after an episode of reflux has occurred.
CONCLUSION

Because of the association of prone positioning with sudden infant death syndrome, its use, even in gastro-oesophageal reflux, is now limited. In this study no benefit for head elevation was noted. Left lateral has been shown to be a suitable alternative to prone for the postural management of symptomatic gastrooesophageal reflux in infancy.

We wish to thank the paediatric nursing staff of Monash Medical Centre, the referring paediatricians for permission to study their patients, and Laura Salomone for her assistance in preparing the manuscript. Supported in part by Helen M Schutt Trust Fund, Truby and Florence Williams Memorial Trust/ANZ Trustees.

1 Carre IJ. Postural treatment of children with a partial thoracic stomach 'hiatus hernia'. Arch Dis Child 1960;35:569-80.

2 Meyers WF, Herbst JJ. Effectiveness of positioning therapy for gastro-esophageal reflux. Pediatrics 1982;69:768-72.

3 Dodds WJ, Hogan WJ, Helm JF, Dent J. Pathogenesis of Dodds WJ, Hogan WJ, Helm JF, Dent J. Pathogene
reflux esophagitis. Gastroenterology 1981;81:376-94.

4 Orenstein SR, Whitington PF. Positioning for prevention of Orenstein SR, Whitington PF. Positioning for preven
gastro-esophageal reflux. $\mathcal{F}$ Pediatr 1983;103:534-7.

5 Jolley SG, Johnson DG, Herbst JJ, Pena A, Garnier R. An assessment of gastro-esophageal reflux in children by extended $\mathrm{pH}$ monitoring of the distal esophagus. Surgery 1978;84:16-24.

6 Ramenovsky ML, Leape LL. Continuous upper esophageal esophageal reflux, pneumonia and apnoeic spells. F Pediatr Surg 1981;16:374-8.

7 Orenstein SR, Whitington PF, Orenstein DM. The infant seat as treatment for gastro-esophageal reflux. $N$ Engl $\mathcal{F}$ Med 1983;309:760-3.

8 Orenstein SR. Prone positioning in infant gastro-esophageal reflux: Is elevation of the head worth the trouble? $\mathcal{F}$ Pediatr 1990;117:184-7.

9 Beal S. Sudden infant death syndrome related to sleeping position and bedding. Med f A ust 1991;155:507-8.

10 Dosition and bedding. Med T, Ponsonby AB, Newman NM, Gibbons LE. Prospective cohort study of prone sleeping position and sudden infant death syndrome. Lancet 1991;337:1244-7.

11 Davies AEM, Sandhu BK. Diagnosis and treatment of gastro-oesophageal reflux. Arch Dis Child 1995;73:82-6

12 Kattwinkwel J, Brooks J, Myerberg D. Positioning and SIDS. Pediatrics 1992;89:1120-6.

13 Blumenthal I, Lealman GT. Effect of posture on gastrooesophageal reflux in the newborn. Arch Dis Child 1982;57: 555-6.

14 Vandenplas Y, Sacre-Smits L. Seventeen-hour continuous esophageal $\mathrm{pH}$ monitoring in the newborn: evaluation of the influence of position in asymptomatic and symptomatic babies. F Pediatr Gastroenterol Nutr 1985;4:356-61.

15 Tam P, Lin LH. Fifteen-hour continuous esophageal pH monitoring: influence of position on gastroesophageal monitoring: influence of position on gastroesophageal reflux amo:

16 Dreizzen E, Escourrou P, Odievre M, Guilleminault C, Gaultier C. Esophageal reflux in symptomatic and asymptomatic infants: postprandial and circadian variations. $\mathcal{F}$ Pediatr Gastroenterol Nutr 1990;10:316-21.

17 Vandenplas Y, De Wolf D, Deneyer M, Sacre L. Incidence of gastroesophageal reflux in sleep, awake, fasted, and postcibal periods in asymptomatic and symptomatic infants. $\mathcal{F}$ Pediatr Gastroenterol Nutr 1988;7:177-80.

18 Strobel CT, Byrne WJ, Ament ME, Euler AR. Correlation of esophageal lengths in children with height: application to the Tuttle test without prior esophageal manometry. $\mathcal{F}$ Pediatr 1979;94:81-4.

19 McMillen IC, Kok JSM, Adamson TM, Deayton JM, Nowak R. Development of circadian sleep-wake rhythms in
preterm and full term infants. Pediatr Res 1991;29:381-4.

preterm and full term infants. Pediatr Res 1991;29:381-4.
20 Sondheimer JM. Continuous monitoring of distal esophageal pH: a diagnostic test for gastroesophageal reflux in geal pH: a diagnostic test for $\mathrm{g}$
infants. $\mathcal{F}$ Pediatr 1980;96:804-7.

21 Vandenplas Y, Goyvaerts $\mathrm{H}$, Helven RN, Sacre L. Gastroesophageal reflux, as measured by 24 -hour $\mathrm{pH}$ monitoring, in 509 healthy infants screened for risk of sudden infant death syndrome. Pediatrics 1991;88:834-40.

22 Schilter B, Le Coutre C, Belli DC. Gastro-oesophageal reflux in children: comparison of different durations, positions and sleep-awake periods of $\mathrm{pH}$ monitoring in the same patient. Eur F Pediatr 1993;152:880-3. 